\title{
КРИТЕРИИ НЕОБХОДИМОСТИ РЕКОНСТРУКЦИИ АВТОМОБИЛЬНЫХ ДОРОГ С УЧЕТОМ ТЕОРИИ ТРАНСПОРТНЫХ ПОТОКОВ ПО СРОКУ ОКУПАЕМОСТИ
}

\author{
Нина Кужель ${ }^{1}$, Андрей Белятынский ${ }^{2}$, Елена Бакулич ${ }^{3}$, Ирина Клименко ${ }^{4}$ \\ ${ }^{1,2}$ Национальный авиационный университет, Киев, Украина \\ ${ }_{3,4}$ Национальный транспортный университет, Киев, Украина

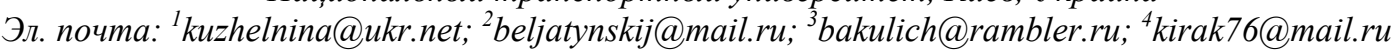

\begin{abstract}
Аннотация. Проведен анализ методики проектирования реконструкции автомобильных дорог на основании теории транспортных потоков с учетом экономических расчетов по сроку окупаемости. На основании теории транспортных потоков показана зависимость «интенсивность движения-скорость». Рассмотрена методика, в основе которой лежит принцип назначения реконструкции автомобильной дороги, исходя из позиции экономической обоснованности реконструкции по сроку окупаемости.
\end{abstract}

Ключевые слова: реконструкция, срок окупаемости, интенсивность движения-скорость, транспортный поток, капитальные вложения, транспортные затраты.

\section{Актуальность темы}

Важным вопросом для экономики государства является правильное назначение срока реконструкции автомобильных дорог. Под реконструкцией понимается переход дороги в более высокую категорию с изменением геометрических параметров дороги и улучшением качества дорожных покрытий. Реконструкция дороги требует комплексного улучшения всех её элементов, однако во время реконструкции нецелесообразно перестраивать все элементы согласно техническим условиям для проектирования новых дорог (Хомяк 1983; Белятынский и др. 1990; Білятинський и др. 1997, 1998; Заворицкий 1996).

Проектирование дороги осуществляется на перспективный период с учетом ежегодного увеличения интенсивности движения. Однако с течением времени, а также с увеличением значения дороги возникает необходимость в повышении нормативных требований. На основании расчетов перспективной интенсивности, наблюдений за скоростью и составом движения, а также с учетом количества и сложности ДТП проводятся экономические исследования, касающиеся обоснования необходимости реконструкции дороги. Также одной из причин реконструкции дороги может быть резкое ухудшение экологического состояния придорожной полосы. В связи с этим необходимо решать такие проблемы, как повышение пропускной способности дороги, улучшение безопасности движения, уменьшение загрязнения окружаю- щей среды, экономия горючего, рациональное использование ресурсов и улучшение комфортности движения по дороге в рамках разработки проекта реконструкции дороги (Белятынский и др. 1990; Білятинський и др. 1997, 1998).

Специфика транспортных инвестиций заключается в очень высоких рисках: этот рынок требует серьезных финансовых вливаний, а отдача приходит не слишком быстро. Транспортная отрасль - достаточно капиталоемкий бизнес, поэтому для инвестирования следует обладать существенным объемом денежных средств.

\section{Решение проблемы}

Реконструкция дороги назначается при достижении интенсивности движения, соответствующей нижней границе более высокой категории дороги. Согласно нормативным документам эта интенсивность движения имеет следующие значения:

- I категория - более 14000 авт./сутки;

- II категория - 14000 авт./сутки;

- III категория - 5000 авт./сутки;

- IV категория - 2500 авт./сутки;

- V категория - 300 авт./сутки.

Однако эти значения интенсивности движения не всегда являются достаточным аргументом для проведения реконструкции.

Решающим аргументом для проведения реконструкции автомобильной дороги являются экономиче- 
ские расчеты. На основании расчетов определяется срок, за который могут окупиться капитальные затраты на реконструкцию (1):

$T=\frac{K}{\Delta E} \leq 8,4$ года,

где: $T$ - срок, за который могут окупиться затраты; $K$ - капитальные затраты на реконструкцию дороги; $\Delta E$ - экономия транспортных затрат за первый год эксплуатации дороги.

Под транспортными затратами понимается разница в цене автомобилей/часов за 1 год до и после реконструкции (Білятинський и др. 1997, 1998):

$\Delta E=E_{\partial}-E_{n}$,

где $E_{\partial}$ - цена авт./ч за 1 год до реконструкции дороги; $E_{n}$ - цена авт./ч за 1 год после проведения реконструкции.

Цена авт./ч за 1 год определяется по формуле:

$E=\left(L_{\partial o p} / V_{c p c}\right) \cdot N \cdot 365$,

где: $L_{\partial о р}$ - длина дороги, км; $V_{c p c}-$ средняя скорость движения, авт./сутки; $C$ - цена одного автомобиля за 1 час работы, грн.; $N$ - суточная интенсивность движения, авт./сутки.

Рассмотрим зависимость «интенсивность движения-скорость» с точки зрения теории транспортных потоков. Эта зависимость установлена на основании «гидродинамической» теории и теории «следования за лидером». В результате получена следующая функциональная зависимость:

$N=V_{c p} \cdot \frac{q_{\max }}{L^{V} p^{/ V} 0}$,

где: $N$ - интенсивность движения авт./час по полосе движения; $v_{c p}$ - средняя скорость транспортного потока, км/ч; $\quad v_{0}$ - средняя скорость, соответствующая пропускной способности полосы движения ( $v_{0}=$ 25 км/ч); $q_{\max }$ - максимальная плотность транспортного потока в заторе, авт./км; $L$ - длина автомобиля, м.

Каждая математическая модель должна иметь ограничение или определенную зону применения. В данном случае ограничением может быть скорость движения автомобилей при свободном режиме движения или, как её еще называют, скорость свободного движения (рис. 1).

Кривая $F(N, V)$ отражает колонное движение автомобилей по полосе движения. Таким образом, интенсивность движения - $N_{\text {II }}, N_{\text {III }}, N_{\text {IV }}$ - соответствует колонному движению при скорости, соответствую-

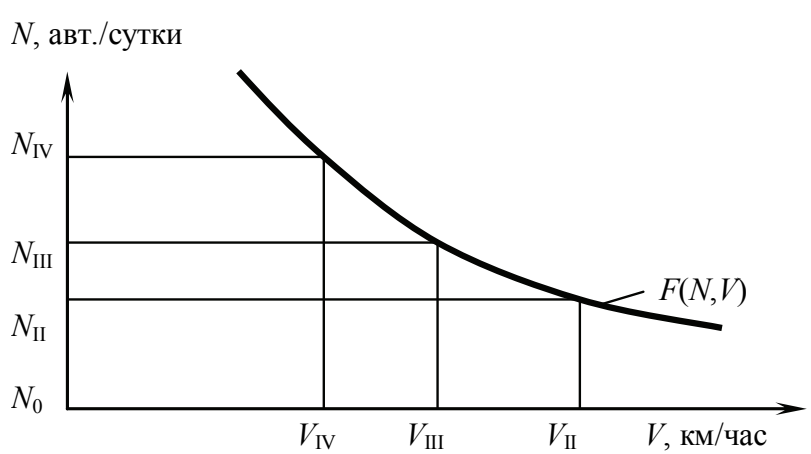

Рис. 1. Зависимость между интенсивностью и скоростью движения транспортного потока

1 pav. Judejimo intensyvumo ir greičio priklausomybė

Fig. 1. Relationship between traffic intensity and speed of traffic flow

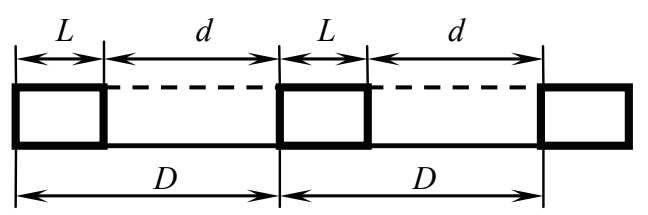

Рис. 2. Взаимоотношение между динамическими габаритами при колонном движении: $L$ - длина автомобиля; $d$ - дистанция между автомобилями, соответствующая данной скорости движения; $D$ - динамический габарит

2 pav. Automobilių judejimas kolonoje ir dinaminiai gabaritai: $L$ - automobilio ilgis; $d$ - atstumas tarp automobilių esant konkrečiam judejjimo greičiui; $D$ - dinaminis gabaritas

Fig. 2. Relationship between the dynamic clearance limits for traffic in column: $L$ - the vehicle's length; $d$ - the distance between the vehicles corresponding to a particular traffic speed; $D$ - the dynamic clearance

щей скорости свободного движения соответствующих категорий дорог.

В интервалах движения автомобиля от уровня $N_{0}$ до $N_{\mathrm{II}}, N_{\mathrm{III}}, N_{\mathrm{IV}}$ режимы движения автомобилей изменяются от свободного до колонного. Когда значения интенсивности движения достигают величин $N_{\text {II }}, N_{\text {III }}$, $N_{\text {IV }}$, то соответственно уменьшается скорость движения транспортного потока $V_{\mathrm{IV}}, V_{\mathrm{III}}, V_{\mathrm{II}}$.

Понятно, что при достижении этих величин динамичный габарит следует за динамичным габаритом без интервалов, как видно на рис. 2.

В таком случае увеличение интенсивности движения вызывает уменьшение дистанции и скорости движения.

Реконструкцию дороги можно осуществить при условии, что интенсивность движения будет:

- на дорогах IV категории - 1000 авт./сутки или - 100 авт./ч - 50 авт./час по полосе движения;

- на дорогах III категории - 3000 авт./сутки или - 150 авт./ч по полосе движения; 
- на дорогах II категории - 7000 авт./сутки или 350 авт./ч по полосе движения.

Интервалы интенсивности движения, когда можно проводить реконструкцию дорог, должны быть:

- с IV категории на III - $1000-N_{\text {III }}$;

- с III категории на II - $3000-N_{\mathrm{II}}$;

- c IV категории на II - $3000-N_{\text {II. }}$

Переход дороги в I категорию может быть осуществлен в случае, если интенсивность движения будет соответственно равна или больше 4500 авт./сутки на полосу движения.

Так как разница в скоростях движения на дорогах III и IV категорий составляет от 0,1 до 2 км/ч, то при любых значениях интенсивности движения реконструкция будет экономически невыгодна, а из-за незначительной экономии транспортных затрат срок окупаемости будет составлять величину, значительно превышающую 8,4 года.

Таким образом, можно сделать следующие выводы из вышесказанного:

1. Реконструкцию автомобильных дорог III и IV категорий можно проводить при интенсивности движения, соответствующей скорости свободного движения второй категории $\left(N_{\mathrm{II}}\right)$.

2. Если интенсивности движения по дороге отвечают скоростям движения данной категории (IV, III и II), то необходим переход на дорогу I категории.

3. Скорость движения на дорогах IV, III и II категорий не изменится, пока интенсивность движения не достигнет величины $N_{\mathrm{IV}}, N_{\mathrm{III}}$ или $N_{\mathrm{I}}$.

Рассмотрим конкретный пример рассчитанного нами назначения реконструкции автомобильной дороги III категории при интенсивности движения 3000 авт./сутки, или 150 авт./ч по полосе движения.

Состав транспортного потока:

- 50\% легковых автомобилей;

- 50\% грузовых автомобилей.

Скорость свободного движения:

- по дорогам III категории - 64,2 км/ч;

- по дорогам II категории - 69,5 км/ч.

Длина дороги составляет 1 км.

Экономия транспортных затрат за 1 год: $\Delta E_{1}=1294,29$ грн. при $\mathrm{C}=1$ грн. за 1 авт./год; $\Delta E_{5}=6471,45$ грн. при $\mathrm{C}=5$ грн. за 1 авт./год; $\Delta E_{10}=12942,9$ грн. при $\mathrm{C}=10$ грн. за 1 авт./год.

Соответственно максимальные капиталовложения на реконструкцию 1 км дороги составят: $K_{1}=E \cdot 8,4$.

\section{Научная новизна}

Реконструкция автомобильной дороги назначается при достижении верхней границы интенсивности движения для данной категории на перспективу. С экономической точки зрения реконструкция дороги должна назначаться при определении срока окупаемости $\leq 8,4$ года. Окупаемость определяется по формуле:

$T_{o \kappa}=\frac{K}{E_{\partial}-E_{n}}$,

где: $E_{\partial}$ - ежегодные транспортные затраты до реконструкции, грн.; $E_{n}$ - транспортные затраты после реконструкции, грн.; $K$ - капитальные вложения, грн.

Величина транспортных затрат зависит от средней скорости движения транспортного потока. Данная методика позволяет решить вопросы реконструкции автомобильных дорог на основании определения срока окупаемости (соотношения капитальных затрат и экономии транспортных затрат). Изза этого возможны варианты перевода автомобильных дорог IV-II категорий в I категорию, если интенсивность движения на данный период составляет $\geq 7000$ авт./сутки. Переход из одной категории в более высокую категорию проводится лишь после определения срока окупаемости. Если срок окупаемости больше 8,4 лет, реконструкция автомобильной дороги будет экономически невыгодной.

В результате проведенных исследований за критерий необходимости перевода системы «дорожные условия-транспортный поток-среда» из одного состояния в другое выбран функционал, выражающий разницу в приведенных затратах экономики государства до и после реконструкции дороги.

В идеальном случае:

$\Delta B=B_{\partial p}-\left(B_{n p}+B_{p}\right)$,

где: $B_{\partial p}-$ приведенные затраты экономики государства до реконструкции дороги, грн.; $B_{n p}-$ приведенные затраты экономики государства после реконструкции, грн.; $B_{p}$ - затраты на реконструкцию дороги, грн.

Ввиду сложности математической конкретизации этого функционала в процессе исследований отдельно рассматривались параметры, определяющие систему. Проведена работа по их минимизации. Определение минимума параметров в общем случае не 
обеспечивает оптимизацию общего критерия, однако позволяет получить рациональное решение, достаточно близкое к оптимальному.

\section{Выводы}

В процессе реконструкции переводить дорогу следует в ту категорию, для которой функционал (6) примет максимальное значение. Значение функционала, близкое к максимальному, можно достичь при минимизации параметров, количества ДТП, а также при наличии экономически обоснованной интенсивности и режима движения. Таким образом, при переводе дорог более низких категорий в более высокие необходимо учитывать следующие факторы: экономически обоснованные интенсивность движения и количество обгонов, повышение безопасности движения и обеспечение условий охраны окружающей среды.

В основе рассмотренной нами методики лежит принцип назначения реконструкции автомобильной дороги, исходя из позиции экономической обоснованности реконструкции по сроку окупаемости (срок окупаемости автомобильной дороги не должен превышать 8,4 года). Целесообразно проводить реконструкцию с учетом всех затрат национальной экономики.

Исходя из вышеизложенного, с учетом затрат национальной экономики можно сделать вывод о том, что реконструкцию автомобильной дороги необходимо назначать лишь при соответствующих экономических расчетах. При несоответствии затрат национальной экономики срокам окупаемости реконструкция экономически нецелесообразна, даже если разные методики показали ее необходимость. Выходом из данной ситуации является пересмотр условий движения по автомобильной дороге, ее улучшение или частичная перестройка ее элементов.

\section{Литература}

Белятынский, А. А.; Василенко, Л. В.; Романюха, А. М. 1990. Проектирование автомобильных дорог с учетом экономии энергоресурсов. Киев: Будивэльнык. 104 с.

Білятинський, О. А.; Заворицький, В. Й.; Старовойда, В. П.; Хом'як, Я. В. 1997. Проектування автомобільних доріг. У двох частинах. Частина 1. Київ: Вища школа. 518 с.

Білятинський, О. А.; Заворицький, В. Й.; Старовойда, В. П.; Хом'як, Я. В. 1998. Проектування автомобільних доріг. У двох частинах. Частина 2. Київ: Вища школа. 416 с.

Заворицкий, В. И.; Старовойда, В. П.; Белятынский, А. А.; Кравченко, В. Г.; Кузьмичев, В. Т.; Коркушко, М. М.; Кизима, С. С. 1996. Проектирование и строительство автомобильных дорог: Справочник. Київ: Техніка. $383 \mathrm{c}$.

Хомяк, Я. В. 1983. Проектирование сетей автомобильных дорог. Москва: Транспорт. 207 с.

\section{AUTOMOBILIUU KELIU REKONSTRUKCIJOS KRITERIJAI VERTINANT TRANSPORTO SRAUTU TEORIJĄ IR ATSIPIRKIMO TERMINĄ}

\section{N. Kužel, A. Beliatynskij, J. Bakulič, I. Klimenko}

Santrauka

Analizuojama automobilių kelių rekonstrukcijos projektavimo metodika remiantis transporto srautų teorija ir atsipirkimo termino ekonominiais skaičiavimais.

Remiantis transporto srautų teorija nagrinejjama priklausomybe ,judèjimo intensyvumas - greitis“.

Pateikta metodika, kurios pagrindas yra automobiliu kelio rekonstrukcijos parinkimo principas, ekonomiškai pozityviai ir motyvuotai vertinant atsipirkimo terminą.

Reikšminiai žodžiai: automobilių kelias, rekonstrukcija, atsipirkimo terminas, judejimo intensyvumas, greitis, transporto srautas, sąnaudos.

\section{ROAD RECONSTRUCTION CRITERIA TAKING INTO ACCOUNT THE THEORY OF TRAFFIC FLOWS AND REPAY TIME}

\section{N. Kuzhel, A. Beljatynskij, O. Bakulich, I. Klimenko}

Abstract

The analysis of design methods of road reconstruction based on the theory of traffic flows and economic calculations of its repay time is presented.

The relationship between traffic intensity and speed is shown by considering the theory of traffic flows.

The methods, taking into account the principle of effectiveness of road reconstruction based on its repay time, are discussed.

Keywords: road, reconstruction, repay time, traffic intensity, speed, traffic flow, investments, expenses. 